\title{
Effect of the extraction of Perilla frutescens treatment on quality of fresh-cut red cabbage (Brassica oleracea)
}

\begin{abstract}
It is vulnerable for red cabbage to decline in quality after cutting, causing seriously financial losses. In this study, the fresh-cut red cabbage was soaked with 50\% Perilla frutescens extraction (50\% extraction), $100 \%$ Perilla frutescens extraction (100\% extraction) and distilled water for $5 \mathrm{~min}$, respectively, to study the effects of Perilla frutescens extraction treatment on quality and antioxidant capacities of fresh-cut red cabbage. The results showed that $50 \%$ extraction treatment remarkable maintained the quality of fresh-cut red cabbage and enhanced the DPPH radical scavenging ability, the effect of Perilla frutescens extraction treatment was distinguished by suppressing the decrease of total phenolic, flavonoids, anthocyanin and Glutathione (GSH) contents and increasing the polyphenol oxidase (PPO), peroxidase (POD), phenylalanine ammonia lyase (PAL) activities. To sum up, $50 \%$ extraction treatment maintained physiological quality and improve the resistance of fresh-cut red cabbage when stored at $4{ }^{\circ} \mathrm{C}$.
\end{abstract}

Keywords: Perilla frutescens, fresh-cut, red cabbage, antioxidant enzyme activity
Volume 6 Issue 3 - 2018

\author{
Aili Jiang, Sitong Gua, Fuhui Zhoua, \\ Wenzhong $\mathrm{Hu}$ \\ College of Life Sciences, Dalian Minzu University, China
}

\author{
Correspondence: Aili Jiang, College of Life Sciences, Dalian \\ Minzu University, Dalian I | 6600, China, Tel + |3840853022, \\ Email jal@dlnu.edu.cn \\ Wenzhong Hu, College of Life Sciences, Dalian Minzu University, \\ Dalian I |6600, China, Tel + |359| |62665, \\ Email hwz@dlnu.edu.cn
}

Received: May 15, 2018 | Published: May 222018
Abbreviations: PPO, polyphenol Oxidase; POD, peroxidase; PAL, phenylalanine ammonia lyase

\section{Introduction}

Perilla frutescens, belongs to Labiatae. P. frutescens family, ${ }^{1}$ is an important edible-medicinal economic crops which widely distributed in Asia, ${ }^{2}$ such as China, Japan and South Korea. Perilla frutescens has been used as a medicinal plant for thousands of years in China for treating depression, anxiety, cough, allergy, poisoning, cancer and intestinal diseases ${ }^{3}$ because of its abundant phenolic compounds, flavonoids, rosmarinic acid, anthocyanin, vitamins and minerals contents. ${ }^{1,4,5}$

Red cabbage (purple-leaved varieties of Brassica oleracea Capitates Group) is popular in the world because of its unique color and a great number of minerals, vitamins and antioxidant substances that are beneficial to human body. ${ }^{6,7}$ The unique color of red cabbage is formed by anthocyanins. ${ }^{8}$ Red cabbage is present mainly as freshcut salads, fresh-cut product was defined as fruits or vegetables that have been trimmed and/ or peeled, or cut into $100 \%$ usable product that is packaged to offer consumers high nutrition, convenience and flavor while still maintaining freshness. Fresh-cut process involved peeling, cutting and other operations that may alter the integrity of tissue, disrupt physiological metabolism and cause stress, ${ }^{9}$ which will affect quality and shelf life of fresh-cut products.

There are a large amount of antioxidant substance in Perilla frutescens and red cabbage, which are both beneficial to human. However, few studies have reported the effects of Perilla frutescens extraction treatment on fresh-cut red cabbage. Therefore, the present study was conducted to investigate the effects of Perilla frutescens extraction application on fresh-cut red cabbage at a temperature of $4^{\circ} \mathrm{C}$.

\section{Materials and methodology}

\section{Materials and sample preparation}

Extraction procedure: Fresh leaves of Perilla frutescens were washed and dried, then filtered after homogenizing, and the liquid extraction was collected. Undamage and disease free red cabbage leaves (7-10 outer layers) that were of a similar stage of color and maturity were cut into $0.5 \mathrm{~cm} \times 5 \mathrm{~cm}$ filaments, fresh-cut red cabbage (1 $\mathrm{kg}$ ) were dipped into 50\% Perilla frutescens extraction, $100 \%$ Perilla frutescens extraction and distilled water (as a control, CK) for $5 \mathrm{~min}$, respectively. The fresh-cut red cabbage was drip dried then stored at plastic trays with sealed polyethylene film at $4^{\circ} \mathrm{C}$.

Anthocyanin content: Anthocyanin content was determined according to Fan et al. ${ }^{10}$ with some modifications. The samples (1g) were homogenized with $5 \mathrm{~mL}$ of precooked $1 \% \mathrm{HCl}$-ethanol on ice then centrifuged at $12000 \mathrm{~g}$ for $20 \mathrm{~min}$ at $4{ }^{\circ} \mathrm{C}$, total anthocyanin content was measured using $\mathrm{pH}$ differential method, each treatment was conducted triple. Results were expressed as gram of cyanidin 3glucoside equivalents per kilogram of fresh weight.

Flavonoids content: Flavonoids content was determined according to Naheed et al. ${ }^{11}$ with some modifications. $0.3 \mathrm{~g}$ of fresh-cut red cabbage, $3.4 \mathrm{~mL}$ of $30 \%$ ethanol, $0.15 \mathrm{~mL}$ of $0.5 \mathrm{~mol} \mathrm{~L}^{-1} \mathrm{NaNO}_{2}$ and $0.15 \mathrm{~mL}$ of $0.3 \mathrm{~mol} \mathrm{~L}^{-1} \mathrm{AlCl}_{3}$ were mixed. After $5 \mathrm{~min}, 1 \mathrm{~mL}$ of $1 \mathrm{~mol}$ $\mathrm{L}^{-1} \mathrm{NaOH}$ was added to the reaction system. The absorbance was measured at $506 \mathrm{~nm}$. The flavonoid concentration was calculated from a calibration curve using rutin as the standard. All concentrations were expressed as grams per kilogram on a fresh weight basis.

Total phenolic content: Total phenolic content was determined by Folin-Ciocalteu method. ${ }^{12} 1 \mathrm{~g}$ of sample was added into $5 \mathrm{~mL}$ of precooked $1 \%$ hydrochloric acid-methanol solution, then ice homogenized and centrifuged at $13000 \mathrm{~g}$ at $4{ }^{\circ} \mathrm{C}$ for $20 \mathrm{~min}$. The absorbance of supernatant at $760 \mathrm{~nm}$ was measured and the level 
of total phenolics compounds was calculated using phenolics as a standard. Three replicates were conducted for each treatment.

Polyphenol oxidase (PPO) activity: For measurement of PPO activity, fresh-cut red cabbage $(5 \mathrm{~g})$ were homogenized with $20 \mathrm{~mL}$ of ice-cold citric acid buffer $(0.2 \mathrm{M}, \mathrm{pH} 6.8)$ then centrifuged at $10,000 \mathrm{~g}$ for $30 \mathrm{~min}$ at $4^{\circ} \mathrm{C} .2 \mathrm{~mL}$ of citric acid buffer (pH 6.8$), 1 \mathrm{~mL}$ of $100 \mathrm{mM}$ 4-methylcatechol and $2 \mathrm{~mL}$ of the supernatant were used to carry out the assay. The increase in absorbance at $398 \mathrm{~nm}$ at $25^{\circ} \mathrm{C}$ within $2 \mathrm{~min}$ was recorded. The PPO activity was expressed as one unit. One unit of activity was defined as the amount of enzyme required to cause an increase of one absorbance unit at $398 \mathrm{~nm}$ in one minute. ${ }^{13}$

Peroxidase (POD) activity: POD activity was determined by method described by Wang et al. ${ }^{14} 2 \mathrm{~g}$ (fresh weight) of tissue was ground in $6 \mathrm{~mL}$ of $0.1 \mathrm{M}$ ice-cold, sodium phosphate buffer $(\mathrm{pH} 7.8)$. The reaction solution contained $1 \mathrm{~mL}$ of $0.1 \mathrm{~mol} \mathrm{~L}^{-1}$ sodium phosphate buffer (pH 7.8), $0.9 \mathrm{~mL}$ of $0.2 \%$ Guaiacol, $0.5 \mathrm{~mL}$ of enzyme extract, and $0.6 \mathrm{~mL}$ of $0.3 \% \mathrm{H}_{2} \mathrm{O}_{2}$. The change in absorbance at $470 \mathrm{~nm}$ was recorded every $5 \mathrm{~s}$. The POD activity was expressed as one unit. One unit of activity was defined as the amount of enzyme required to cause an increase of one absorbance unit at $470 \mathrm{~nm}$ in one minute.

Phenylalanine ammonia lyase (PAL) activity: For measurement of PAL activity, $0.4 \mathrm{~g}$ of fresh-cut red cabbage tissues was extracted with $6 \mathrm{~mL}$ of extraction buffer $\left(0.1 \mathrm{~mol} \mathrm{~L}^{-1}\right.$ borate, $0.1 \%$ mercaptoethanol; $\mathrm{pH} 8.8$ ). The extracts were centrifuged at $10600 \mathrm{~g}$ for $15 \mathrm{~min}$ at $4^{\circ} \mathrm{C}$. The assay was performed by $200 \mu \mathrm{L}$ of the extract added to $2.3 \mathrm{~mL}$ of reaction buffer (borate $0.1 \mathrm{M}, 10 \mathrm{mM}$ phenylalanine; $\mathrm{pH} 8.8$ ) at $40^{\circ} \mathrm{C}$ for $1 \mathrm{~h}$ and stopped by the addition of $0.5 \mathrm{ml}$ of $5 \mathrm{M} \mathrm{HCl}$. The change in absorbance was read at $290 \mathrm{~nm}$. The PAL activity was expressed as one unit. One unit of activity was defined as the amount of enzyme required to cause an increase of one absorbance unit at $290 \mathrm{~nm}$ in one minute..$^{15}$

Glutathione (GSH) activity: The GSH activity was measured according to Wang \& Zhu. ${ }^{16}$ Samples $(1 \mathrm{~g})$ were homogenized in $5 \mathrm{~mL}$ $1 \%(\mathrm{w} / \mathrm{v})$ saline buffer $[1 \%(\mathrm{w} / \mathrm{v})$ polyvinylpyrrolidone $(\mathrm{PVP}), 1 \mathrm{mM}$ ethylenediaminetetraacetic acid (EDTA)], then centrifuged at $11000 \mathrm{~g}$ for $15 \mathrm{~min}$ at $4^{\circ} \mathrm{C}$, and the supernatants were collected for analysis. The method of GSH measurement is based on the generation of a yellow color when 5, 50 dithiobis (2-nitrobenzoic acid) reacts with $\mathrm{GSH}$. The absorbance was recorded at $412 \mathrm{~nm}$ after $10 \mathrm{~min}$ of reaction. GSH concentrations were expressed on fresh weight basis as mol/g.

DPPH radical scavenging ability: Fresh-cut red cabbage was extracted with $50 \%$ ethanol, then centrifuged at $12000 \mathrm{~g}$ for $20 \mathrm{~min}$ at $4^{\circ} \mathrm{C}$, and the supernatant was collected for determination. $0.1 \mathrm{~mL}$ of supernatant was added to $2.9 \mathrm{~mL}$ of methanol with $120 \mathrm{~mol} \mathrm{~L}^{-1}$ DPPH. An ethanolic solution of DPPH served as control. The result was calculated according to the following formula: DPPH radical scavenging ability $(\%)=100-$ (absorbance of sample/absorbance of control) $\times 100 .^{17}$

Soluble protein: Soluble protein was determined by Coomassie brilliant blue method. ${ }^{18}$

\section{Data analysis}

All data were expressed as mean \pm standard error of the mean (SEM) and SPSS version 22.0 (SPSS Inc., Chicago, IL, USA) was used to test for significant differences $(\mathrm{P}<0.05)$ in mean values between the control and extraction treatment.

\section{Results and discussion}

Fresh-cut market has rapidly expanded in recent decades due to its convenience and deliciousness. However, the appearance and texture of fresh-cut products easily change during storage, such cut-edge browning, chlorophyll and anthocyanin degradation. ${ }^{19}$ Many natural product extracts have been used to maintain the quality of fresh-cut fruit and vegetable due to their safety, efficacy and great potential. ${ }^{20,21}$

Phenolic in plants are the main sources of antioxidant activity. 22 The redox properties of phenolic compounds can act as reducing agents, hydrogen donors, singlet oxygen quenchers and metal chelators. ${ }^{23}$ Foods rich in phenolics have the function of retarding lipid oxidation degradation and controlling diseases such as heart disease through their strong oxidizing power. ${ }^{24}$ There was a loss in anthocyanin, flavonoids and total phenolic content in control and extraction treatments during storage, but $50 \%$ extraction treatment suppressed the decline of these substances compared with the control $(\mathrm{P}<0.05)$ (Figure 1-3), which kept the nutrient content of fresh-cut red cabbage. These results were accord with previous reports in freshcut red cabbage treated by low doses $\mathrm{Cu}^{2+} .25$

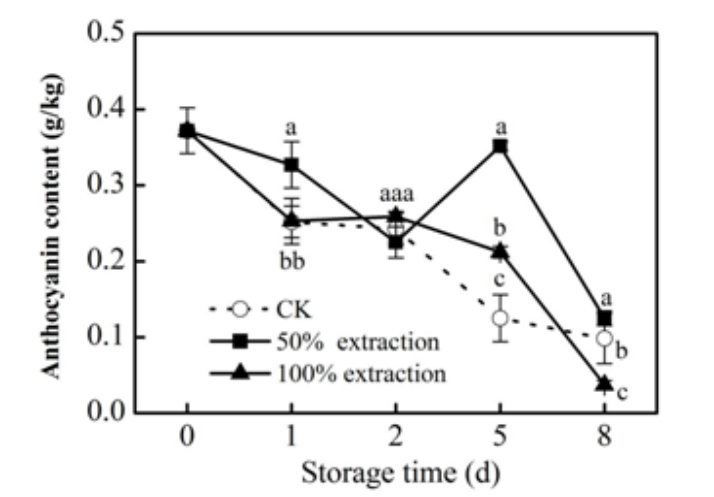

Figure I Effect of Extraction treatment on anthocyanin content of freshcut red cabbage during storage. CK: control. Vertical bars are SD $(n=3)$. The different letters $(a, b, c)$ reveal significant difference at $\mathrm{P}<0.05$ for each day.

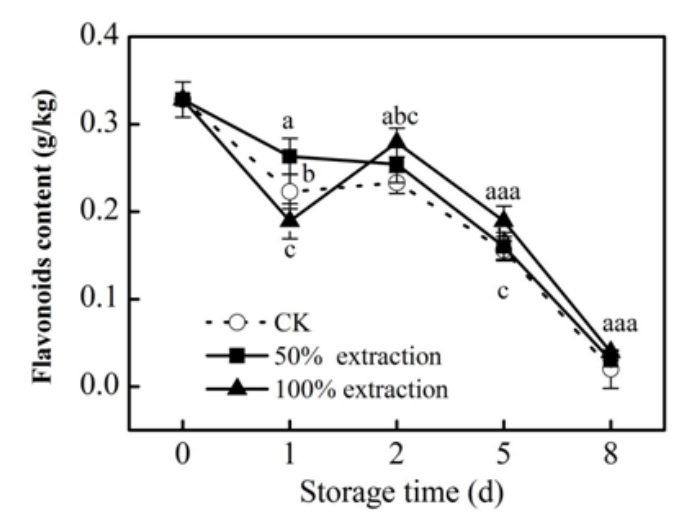

Figure 2 Effect of Extraction treatment on flavonoids content of fresh-cut red cabbage during storage. CK: control. Vertical bars are SD $(n=3)$. The different letters $(a, b, c)$ reveal significant difference at $\mathrm{P}<0.05$ for each day.

PPO participates in the production of reactive oxygen species (ROS), quinones and hydroperoxides in cells and the aggregation of polyphenols, carbohydrates and proteins associated with plant defenses in cell walls. ${ }^{26} \mathrm{We}$ found that extraction treatment stimulated 
the PPO activity (Figure 4), suggesting that extraction treatment may enhanced the resistance of plant. POD can eliminate excess $\mathrm{H}_{2} \mathrm{O}_{2} \cdot{ }^{27} \mathrm{In}$ our study, POD activity was induced by extraction treatment (Figure 5), higher POD activity can increase the antioxidant capacity of freshcut red cabbage, Liang et al. ${ }^{28}$ have found that increased activities of POD and PPO can enhance the resistance in cassava.

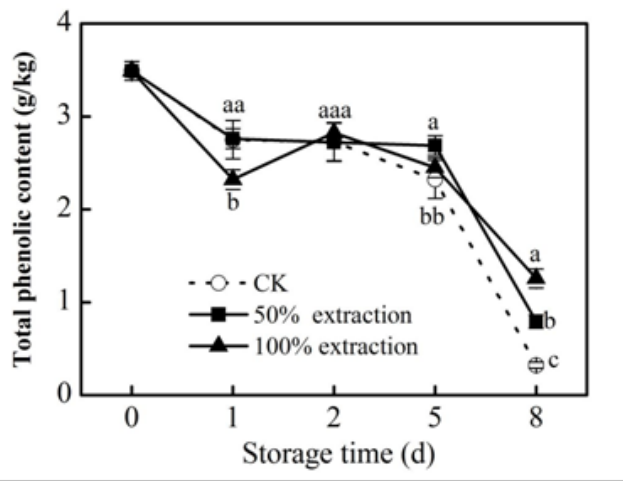

Figure 3 Effect of Extraction treatment on total phenolic content of freshcut red cabbage during storage. CK: control.Vertical bars are SD $(n=3)$. The different letters $(a, b, c)$ reveal significant difference at $\mathrm{P}<0.05$ for each day.

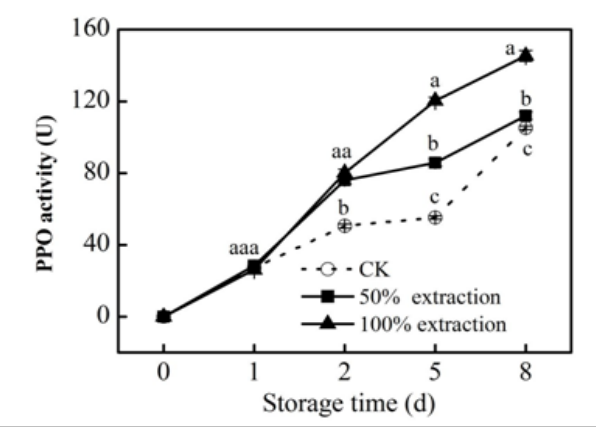

Figure 4 Effect of Extraction treatment on PPO activity of fresh-cut red cabbage during storage. CK: control. Vertical bars are SD $(n=3)$. The different letters $(\mathrm{a}, \mathrm{b}, \mathrm{c})$ reveal significant difference at $\mathrm{P}<0.05$ for each day.

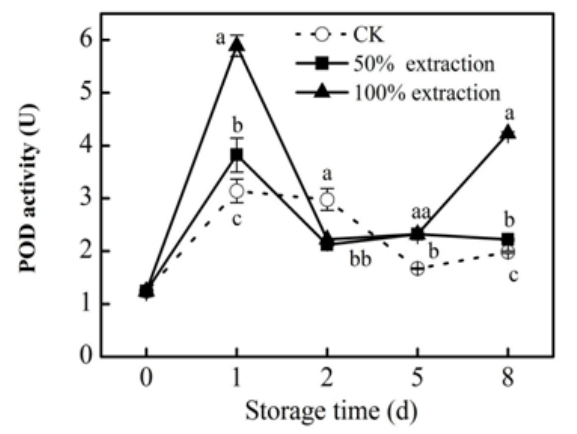

Figure 5 Effect of Extraction treatment on POD activity of fresh-cut red cabbage during storage. CK: control.Vertical bars are SD $(n=3)$. The different letters $(\mathrm{a}, \mathrm{b}, \mathrm{c})$ reveal significant difference at $\mathrm{P}<0.05$ for each day.

The lignifications on cutting surface of red cabbage can resistant the infestation of pathogen, phenylpropanoids pathway regulate formation of callus, PAL plays a pivotal role in this pathway. ${ }^{29,30}$ In our research, PAL activity decreased in treatment group at the first day, then increased on $2 \mathrm{~d}$, following declined until $5 \mathrm{~d}$, then significantly increased, it is worth noting that the PAL activity in CK at $8 \mathrm{~d}$ is lower than $0 \mathrm{~d}$, and the activity of PAL in extraction treatments were always higher than that of the control $(\mathrm{P}<0.05)$, and the effect of $50 \%$ extraction treatment was the best (Figure 6), indicating that the extraction treatment helps to enhance the resistance of the freshcut red cabbage tissue, Our findings are in agreement with studies reported by Kumar \& Lulai. ${ }^{30,31}$

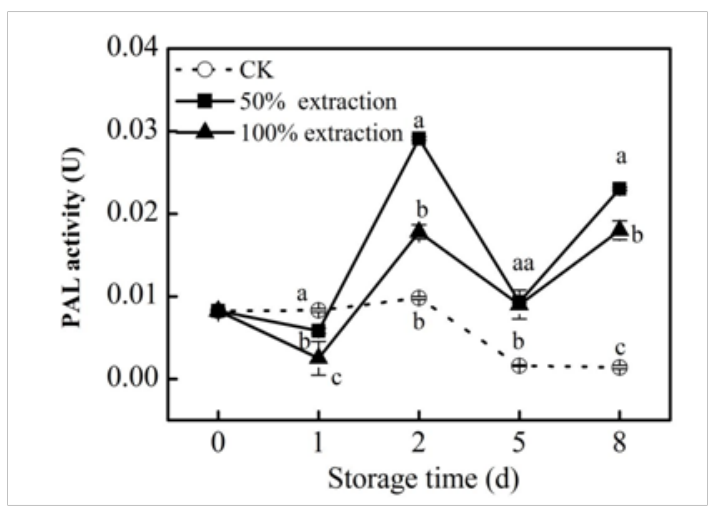

Figure 6 Effect of Extraction treatment on PAL activity of fresh-cut red cabbage during storage. CK: control. Vertical bars are SD $(n=3)$. The different letters $(a, b, c)$ reveal significant difference at $P<0.05$ for each day.

GSH plays an important role in keeping cellular redox status, ${ }^{32}$ and has an significant function in antioxidant protection. ${ }^{33}$ We found that GSH content exhibits a fluctuating trend, a higher content were observed in red cabbage treated with extraction (Figure 7) $(\mathrm{P}<0.05)$. The DPPH free radical scavenging ability can reflect the antioxidant activity of fresh-cut red cabbage. Compared with the control, the $50 \%$ extraction treatment significantly enhanced the ability of DPPH free radical scavenging at days 1 and 8 (Figure 8), these findings may related to higher contents of total phenolic, flavonoid, anthocyanin and GSH and higher level of POD activity in fresh-cut red cabbage.

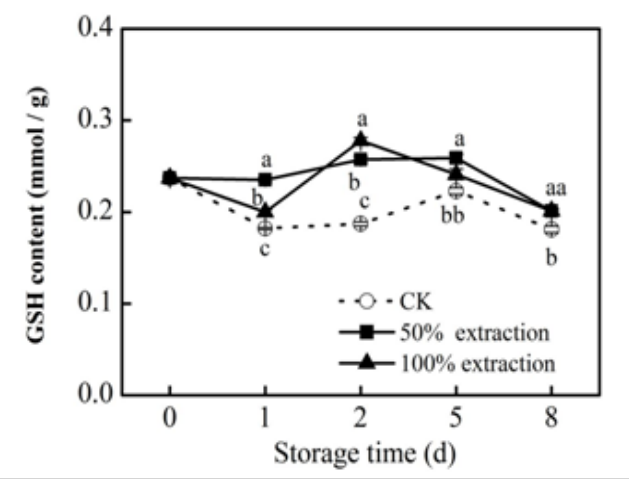

Figure 7 Effect of Extraction treatment on GSH content of fresh-cut red cabbage during storage. CK: control. Vertical bars are SD $(n=3)$. The different letters $(a, b, c)$ reveal significant difference at $\mathrm{P}<0.05$ for each day.

In our study, the soluble protein content of extraction treatment were significantly higher control $(\mathrm{P}<0.05)$, the effect of $50 \%$ extraction treatment was more pronounced (Figure 9). This result may be more related to the functional enzymes in extraction treated fresh-cut red cabbage. 


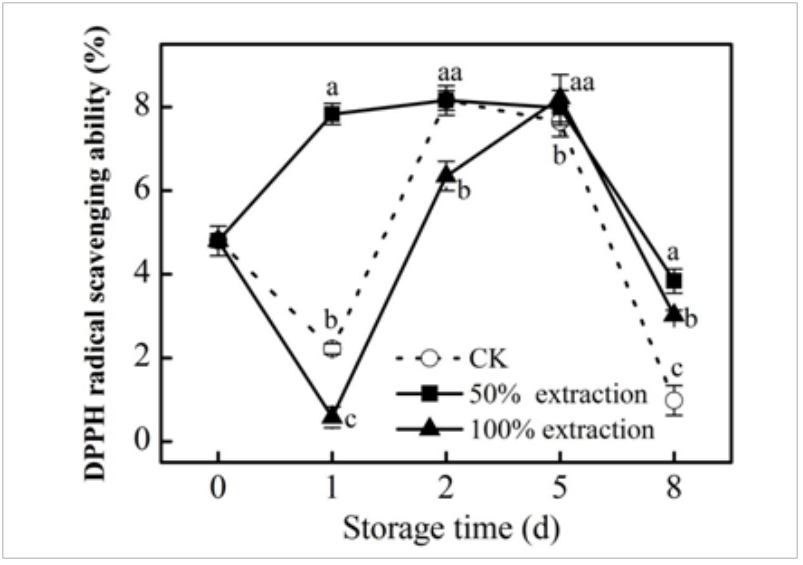

Figure 8 Effect of Extraction treatment on DPPH radical scavenging activity of fresh-cut red cabbage during storage. CK: control. Vertical bars are SD $(n=3)$. The different letters $(a, b, c)$ reveal significant difference at $P<0.05$ for each day.

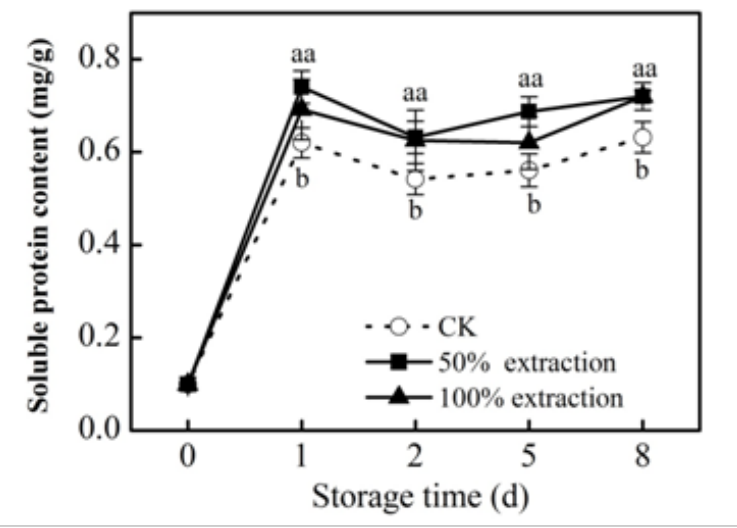

Figure 9 Effect of Extraction treatment on soluble protein content of freshcut red cabbage during storage. CK: control. Vertical bars are SD $(n=3)$. The different letters $(a, b, c)$ reveal significant difference at $\mathrm{P}<0.05$ for each day.

\section{Conclusion}

In conclusion, we found that Perilla frutescens extraction treatment maintained the quality of fresh-cut red cabbage, the effect of $50 \%$ extraction treatment is better than $100 \%$ extraction treatment, the mechanism of these were the likely to hold the content of antioxidant components, enhance the activity of antioxidant enzymes, and improved fresh-cut red cabbage tissue resistance.

\section{Acknowledgements}

This study was supported by the Thirteenth Five-Year Plan' for National Key R\&D Program of China (Grant No. 2016YFD0400903).

\section{Conflict of interest}

The author declares that there is none of the conflicts.

\section{References}

1. Lin ES, Chou HJ, Kuo PL, et al. Antioxidant and antiproliferative activities of methanolic extracts of Perilla frutescens. Journal of Medicinal Plants Research. 2010;4(6):477-483.
2. Yu H, Qiu JF, Ma LJ, et al. Phytochemical and phytopharamacological review of Perilla frustescens L. (Labiatae), a traditional ediblemedicinal herb in China. Food Chem Toxicol. 2017;108(Pt B):375-391.

3. Yang SY, Hong C, Lee $\mathrm{H}$, et al. Protective effect of extracts of Perilla frutescens treated with sucrose on tert butyl hydroperoxide induced oxidative hepatotoxicity in vitro and in vivo. Food Chem. 2012;133(2):337-343.

4. Feng LJ, Yu CH, Ying KJ, et al. Hypolipidemic and antioxidant effects of total flavonoids of Perilla frutescens leaves in hyperlipidenia rat induced by high-fat diet. Food Research International. 2011;44(1):404-409.

5. Saita E, Kishimoto Y, Tani M, et al. Antioxidant activities of Perilla frutescens against low-density lipoprotein oxidation in vitro and in human subjects. J Oleo Sci. 2012;61(3):113-120.

6. Volden J, Borge GIA, Bengtsson GB, et al. Effect of thermal treatment on glucosinolates and antioxidant-related parameters in red cabbage (Brassica oleracea L. ssp. capitata f. rubra). Food Chemistry. 2008;109(3):595-605.

7. Wiczkowski W, Szawara-Nowak D, Topolska J. Red cabbage anthocyanins: profile, isolation, identification, and antioxidant activity. Food Research International. 2013;51(1):303-309.

8. Wiczkowski W, Szawara-Nowak D, Topolska J. Changes in the content and composition of anthocyanins in red cabbage and its antioxidant capacity during fermentation, storage and stewing. Food Chem. 2015;167:115-123.

9. Cavaiuolo M, Cocetta G, Bulgari R, et al. Identification of innovative potential quality markers in rocket and melon fresh-cut produce. Food Chem. 2015; 188:225-233.

10. Fan L, Shi J, Zuo J, et al. Methyl jasmonate delays postharvest ripening and senescence in the non-climacteric eggplant (Solanum Melongena, 1.) fruit. Postharvest Biology \& Technology. 2016;120:76-83.

11. Naheed Z, Cheng Z, Wu C, et al. Total polyphenols, total flavonoids, allicin and antioxidant capacities in garlic scape cultivars during controlled atmosphere storage. Postharvest Biology \& Technology. 2017;131:39-45

12. Pirie A, Mullins MG. Changes in anthocyanin and phenolics content of grapevine leaf and fruit tissues treated with sucrose, nitrate, and abscise acid. Plant Physiology. 1976;58(4):468-472.

13. Chen $\mathrm{C}, \mathrm{Hu} \mathrm{W}, \mathrm{He} \mathrm{Y}$, et al. Effect of citric acid combined with UV-C on the quality of fresh-cut apples. Postharvest Biology \& Technology. 2016;111:126-131.

14. Wang Q, Ding T, Zuo J, et al. Amelioration of postharvest chilling injury in sweet pepper by glycine betaine. Postharvest Biology \& Technology. 2016;112:114-120.

15. Toscano S, Ferrante A, Cherubino L, et al. PAL activities in asparagus spears during storage after ammonium sulfate treatments. Postharvest Biology \& Technology. 2018;140:34-41.

16. Wang B, Zhu S. Pre-storage cold acclimation maintained quality of cold-stored cucumber through differentially and orderly activating ROS scavengers. Postharvest Biology \& Technology. 2017;129:1-8.

17. Wang L, Zhang H, Jin P, et al. Enhancement of storage quality and antioxidant capacity of harvested sweet cherry fruit by immersion with $\beta$ aminobutyric acid. Postharvest Biology \& Technology. 2016;118:71-78.

18. Smith BJ. Quantification of protein by staining in polyacrylamide gels. The Protein Protocols Handbook. 1996. p. 167-172.

19. Toivonen PMA, Brummell DA. Biochemical bases of appearance and texture changes in fresh-cut fruit and vegetables. Postharvest Biology \& Technology. 2008;48(1):1-14. 
20. Ayala-Zavala JF, Oms-Oliu G, Odriozola-Serrano I, et al. Biopreservation of fresh-cut tomatoes using natural antimicrobials. European Food Research and Technology. 2008;226(5):1047-1055.

21. Bai J, Baldwin EA, Soliva-Fortuny RC, et al. Effect of pretreatment of intact 'Gala' apple with ethanol vapor, heat, or 1-methylcyclopropene on quality and shelf life of fresh-cut slices. Journal of the American Society for Horticultural Science. 2004;129(4):583-593.

22. Kähkönen MP, Hopia AI, Vuorela HJ, et al. Antioxidant activity of plant extracts containing phenolic compounds. J Agric Food Chem. 1999;47(10):3954-3962.

23. Rice-Evans CA, Miller NJ, Bolwell PG, et al. The relative antioxidan activities of plant-derived polyphenolic flavonoids. Free Radical Res. 1995;22(4):375-383.

24. Hertog MGL, Feskens EJM, Hollman PCH, et al. Dietary antioxidant flavonoids and risk of coronary heart disease: the Zutphen elderly study. Lancet. 1993;342(8878):1007-1011.

25. Posmyk MM, Kontek R, Janas KM. Antioxidant enzymes activity and phenolic compounds content in red cabbage seedlings exposed to copper stress. Ecotoxicol Environ Saf. 2009;72(2):596-602.

26. Goel N, Paul PK. Plant age affects elicitation of polyphenol oxidase activity by neem extract in Solanum lycopersicum against Pseudomonas syringae pv. tomato. Israel Journal of Plant Sciences. 2015;62(4):283-293

27. Yan J, Song Y, Li J, et al. Forced-air precooling treatment enhanced antioxidant capacities of apricots. Journal of Food Processing and Preservation. 2017;42(1):e13320.

28. Liang $\mathrm{X}$, Chen $\mathrm{Q}, \mathrm{Lu} \mathrm{H}$, et al. Increased activities of peroxidase and polyphenol oxidase enhance cassava resistance to Tetranychus urticae. Exp Appl Acarol. 2017;71(3):195-209.

29. Toscano S, Ferrante A, Leonardi C, et al. Pal activities in asparagus spears during storage after ammonium sulfate treatments. Postharvest Biology \& Technology. 2018;140:34-41.

30. Kumar GNM, Lulai EC. Age-induced loss of wound-healing ability in potato tubers is partly regulated by ABA. Planta. 2010;232(6):1433-1445.

31. Rennenberg H. Glutathione metabolism and possible biological roles in higher plants. Phytochemistry. 1980;21(12):2771-2781

32. Noctor G, Foyer $\mathrm{CH}$. Ascorbate and glutathione: keeping active oxygen under control. Annu Rev Plant Physiol Plant Mol Biol. 1998;49:249-279. 